\title{
ADULT ATTACHMENT STYLE AND SUICIDALITY
}

\author{
Mario Miniati, Antonio Callari \& Stefano Pini \\ Department of Clinical and Experimental Medicine, Section of Psychiatry, University of Pisa, Pisa, Italy
}

received: 2.1.2017;

revised: 3.5.2017;

accepted: 5.6.2017

\section{SUMMARY}

Background: There is evidence in the literature that adverse early attachment experiences and subsequent attachment insecurities during adulthood would lead to pessimism, low self-esteem, hopelessness and, ultimately, to suicide risk.

Subjects and methods: This paper aims to review finding on the link between attachment style and suicidality. We searched the literature using the database of the U.S. National Center for Biotechnology Information (NCBI)-MedLine/Pubmed system from January 1992 until December 2016. We started with 1992 because, as far as we know, there are no published studies exploring the relationship between suicide and insecure attachment before that year. We considered reports published on the relationship between attachment style and suicidality. We applied several combinations of the following search terms: attachment, adult attachment style and suicidality, suicide, suicidal ideation, suicidal behavior or suicidal thoughts, and suicide attempts. We selected only English language studies.

Results: Research suggests that insecure attachment style, mostly anxious, and unresolved traumas are associated with an increased suicide risk. Few studies prospectively examined clinical course, comorbid psychiatric disorders, familial suicidality or other psychosocial factors.

Conclusions: Further research is needed to highlight the nature of the link between attachment and suicidality. The presence of suicidal ideation and attempts might be a consequence of an underlying interaction between the emergence of psychiatrics symptoms, and the long-lasting presence of inadequate patterns of attachment. Within this context, Separation Anxiety Disorder, categorized in the DSM-5 as a condition not confined to childhood but as an anxiety disorder that may occur through the entire lifespan, might be the a key for the comprehension of this link. From a neurobiological point of view, the role of oxytocin remains unclear.

Key words: DSM-5 - attachment style - suicidal ideation - suicidal behaviors - separation anxiety

\section{INTRODUCTION}

Prevention of suicide is a recognized area of intervention in mental health (Office of the Surgeon General (US), National Action Alliance for Suicide Prevention, US 2012). Studies on suicidal behaviors, especially in patients with depression, identified a number of modifiable risk factors. The area of interpersonal relationships is one of the above-mentioned domains. There is consistent evidence indicating an intimate link between suicidal behaviors and interpersonal difficulties (Weissman 1974, Bongar et al. 2000). Although the interpersonal domain is a recognized area of study in preventing suicide behaviors, few studies examined the risk of suicide from an attachment perspective, especially in adults (Mikulincer \& Shaver 2007). Attachment, as first described by Bowlby (1969), is a biologically based motivational control system to monitor the whereabouts of identified caretakers, and to promote proximity to them with the goal to obtain protection and/or survival. This system is mainly activated in conditions of danger and distress. The caregiver response under these conditions determines the child's physical safety, and, primarily, his inner sense of security. Repeated experiences with caregivers are organized into internal working models of self and attachment figure, that govern the activation of the attachment system, and reflect the child's expectations of future interpersonal interactions. There are three kind of primary attachment styles traditionally described in children but also well represented in adults: i) avoidant, ii) anxious and iii) secure. Subsequently, a fourth attachment category has been described and called 'disorganized' or 'disoriented' or 'unresolved'. It includes those children who demonstrated confused or contradictory behaviors upon the emotional feedback of their caretakers (Ainsworth 1973). People with 'avoidant' attachment, also called 'dismissive' or 'fearful', experience a distant/unresponsive care giving during childhood. They are uncomfortable with closeness in relationships and tend to over-value independence. Anxious people also called 'preoccupied' or 'resistant', describe an unpredictable care giving during early life. They strongly need close relationships, but they feel an intense and persistent fear of abandonment, and often perceive people as 'not so close as they desire'. 'Securely' attached people are characterized by the feeling of being close to significant ones and by the subjective ability to rely on them.

These different attachment patterns have been utilized to identify the ways to build interpersonal relationships across lifetime, and resulted strongly linked to the development of different forms of psychopathology (Blatt \& Levy 2003, Sroufe 2005, Ward et al. 2006). 
The insecure attachment style is correlated with the highest risk of suicidality. In a theoretical exploration of the role of attachment processes in suicidal behaviors, Adam (1994) proposed a developmental model by which attachment insecurities in childhood might represent distal risks for suicidal ideation later in lifetime, through their effects on self-representations, emotion regulation, and interpersonal difficulties. Adverse early attachment experiences and resulting attachment insecurities would lead to pessimism, low self-esteem, hopelessness, and to hinder an adolescent's ability to develop a stable sense of identity. When this vulnerable trait is coupled with an adolescent's current experience of rejection, loss, or disappointment, the experience is transformed into an attachment crisis, accompanied by overwhelming distress and maladaptive defensive reactions that can move a person to self-destruction (Adam 1994). Suicide attempts may follow the avoidant deactivation of the attachment system, which can lead not only to avoidance of interdependence and closeness, but also to rejection of others and of life itself. However, a limited number of retrospective or cross-sectional studies, mostly conducted in adolescents, investigated the association between attachment style and suicidality in clinical and non-clinical samples (de Jong 1992, Adam et al. 1996, Lessard \& Moretti 1998, West et al. 1999, Fergusson et al. 2000, Di Filippo \& Overholser 2000, Riggs \& Jacobvitz 2002, Salzinger et al. 2007, Stepp et al. 2008, Zeyrek et al. 2009, Lizardi et al. 2011, Smith et al. 2012, Sheftall et al. 2013).

A recent study examined the predictive effect of attachment on suicidal behavior using a perspective design (Grunebaum et al. 2010). Palitsky et al. (2013) were the first to investigate the relationship between adult attachment style, suicidality and psychopathology in the National Comorbidity Survey Replication database (NCS-R).

The aim of this paper is to review the available literature on the relationship between attachment and suicide related behaviors. We hypothesize that there are psychopathological and neurobiological bridges mediating this relationship.

\section{SUBJECTS AND METHODS}

We searched the literature using the database of the U.S. National Center for Biotechnology Information (NCBI)-MedLine/Pubmed system from January 1992 until December 2016. We considered research reports published on the relationship between attachment style and suicidality. We applied several combinations of the following search terms: attachment, adult attachment style and suicidality, suicide, suicidal ideation, suicidal behavior or suicidal thoughts, and suicide attempts. We selected only English language studies. We started with 1992 because, as far as we know, there are no published studies exploring the relationship between suicide and insecure attachment before that year.

\section{RESULTS AND DISCUSSION}

\section{The Insecure attachment style as predictor of suicidal risk}

A first attempt to systematically explore the presence/absence of secure attachment from parents and peers in a sample of 126 undergraduates (42 with a history of suicidality, namely serious suicidal thoughts or suicidal attempts, 42 currently depressed with no history of suicidality, and 42 controls) is due to de Jong et al. (1992). Students with a history of suicidality showed both the lowest security of attachment on the Inventory of Parent and Peer Attachment (IPPA) (Armsden \& Greenberg 1987) and the least degree of individuation in their current relationships with parents. Students with a history of suicidality rated their parents and mother as 'emotionally absent in childhood' to a significantly higher degree than depressed patients and normal controls. This effect was independent from depression and related to female gender. History of suicidality was associated with family instability and, in a less important degree, with parental divorce. The absence of parents as emotionally available attachment figures 'at the time when such availability is critical' raised vulnerability to suicide in adolescence.

In a case-comparison study, Adam et al. (1996) assessed attachment patterns using the AAI-Attachment Interview for Adults (de Haas et al. 1994) among 133 adolescents in psychiatric treatment and compared adolescents with histories of suicidal behavior $(n=53)$ and severe suicidal ideation $(n=16)$ to those who never experienced suicidal ideation or behaviors $(n=64)$. They found a higher prevalence of preoccupied attachment among suicidal patients than among non-suicidal ones. Moreover, suicidal patients displayed higher levels of disorganization in reasoning when discussing an attachment-related trauma. They were more likely to be classified as suffering from unresolved trauma, suggesting that cognitive disorganization might be an important mediator between traumatic experience and suicidal behavior.

Similar associations were found in a community sample of 233 expectant parents (Riggs \& Jacobvitz 2002). The study explored the association between adult representations of early attachment relationships and a history of individual and family mental health. Parents classified as 'preoccupied' or 'unresolved' in the AAI were more likely to report suicidal ideation than those classified as 'secure'. Regarding family history, unresolved and preoccupied attachments were significantly related to child abuse and parental divorce. Lessard \& Moretti (1998) investigated the relationship between attachment patterns and suicidal ideation in 116 adolescents with severe conduct problems. They assessed on level of current ideation through self-report questionnaires, namely the Youth Self Report of the Ontario Child Health Study Scales (YSR) (Offord et al. 1987); the Beck Depression Inventory (BDI) (Beck et al. 1961), rating also lethality of methods on a subset of the 
sample $(\mathrm{n}=16)$ who, in addition to endorsing current suicidal ideation, presented a plan on a diagnostic interview. Adolescents with predominantly fearful or preoccupied attachment were more likely to endorse suicidal ideation than predominantly secure or dismissing adolescents. Greater lethality in methods of contemplated suicide was positively correlated with preoccupied tendencies.

In a subsequent retrospective case-comparison study, West et al. (1999) evaluated a sample of 187 adolescents (86 of whom with a history of suicidal behaviors) using 6 measures of attachment pattern, including the Adolescent Attachment Questionnaire (AAQ) (West et al. 1998). Depressive symptoms were assessed by the Depression Syndrome Scale of the Youth, Self-Report (YSR) (Achenbach 1991). Suicidality was rated with the Adam Suicidal Ideation and Behavior protocol (1973). The perceived unavailability and the presence of high levels of depressive symptomatology were predictive of subsequent suicidal behaviors. Moreover, a strong association was found between being older and having high levels of angry distress in adolescents with suicidal behaviors.

Di Filippo \& Overholser (2000) investigated the association between suicidal ideation (measured with the Beck Scale for Suicide Ideation (BSI) (Beck \& Steer 1991), depressive symptomatology (measured with Children's Depression Inventory (CDI) (Kovacs 1992) and attachment to parents and peers (measured with the IPPA (Armsden \& Greenberg 1987), in a sample of 59 adolescent psychiatric inpatients. Attachment to mother accounted for a significant variation in levels of depressive symptomatology and suicidal ideation. They also found that attachment to peers accounted for a significant variation in suicidal ideation and depressive symptoms only in female gender. However, after adjusting for the presence of depressive symptoms, attachment variables failed to contribute additional variance in suicidal ideation, suggesting that the link between attachment insecurity and suicidality was mediated by depression.

Stepp et al. (2008) tested, in a predominantly psychiatric sample $(\mathrm{N}=406)$, whether interpersonal problems mediated in a differential way the relationship between attachment styles and suicide related behaviors (i.e., self-harm, suicide attempts, and their co-occurrence). Specifically, higher anxious attachment predicted interpersonal sensitivity, interpersonal aggression, and lack of sociability, which, in turn, were associated with suicide-related behaviors. Additionally, there was a negative association between avoidant attachment and interpersonal sensitivity that increased the risk for selfinjury. The avoidant attachment was not a predictor of suicidal behaviors. The effect of attachment style on self-injury was considered only partially related to interpersonal sensitivity.

Zeyrek et al. (2009) explored the perceived probability of future suicidal behaviors with the Suicide Probability Scale (SPS) (Cull \& Gill 1982) in a sample of 180 university students, and found that there was a significant correlation both with the 'preoccupied' $(\mathrm{p}<0.01)$ and 'fearful' $(p<0.05)$ attachment styles in females.
In the first prospective longitudinal study, examining the predictive effect of attachment security in relation to suicide attempt, in a sample of 136 adult patients with DSM-IV major depressive episodes, Grunebaum et al. (2010) found that less secure/more avoidant attachment measured with Adult Attachment Scale (AAS) (Simpson 1990) predicted an increased risk of suicide attempts during a 1-year follow-up. The use of a selfreport attachment scale and the small sample size represented the main study limitations. However, the fact that avoidant attachment predicted suicide attempt, whereas social adjustment was a better predictor of major depression, supported the view that depression and suicidal behavior were distinct phenomena with some shared variance (Mann et al. 1999).

In an expanded sample four times as large as their prior study $(n=613)$ and including both unipolar and bipolar depressed patients, the same research group found that anxious attachment was correlated with suicide attempt history, after adjusting for quality of attachment (Lizardi et al. 2011). Conversely, the overall social adjustment, measured with the Social Adjustment Scale-Self-Report Version (SAS-SR) (Weissman \& Bothwell 1976) was not correlated. This finding suggested that anxious attachment and work adjustment might be important risk factors for suicidal behaviors in patients with mood disorders. Although results of the second study differed from the results of the first one (in that, anxious rather than avoidant attachment was significant) the finding was consistent with literature exploring the association between insecure attachment of either type and suicidal ideation or behaviors. So they hypothesized that less secure attachment of any kind (be it anxious or avoidant) might increase the risk for suicide attempt (Lizardi et al. 2011).

In a recent cross-sectional study on a sample of 106 women with Major Depression and a history of childhood sexual abuse, Smith et al. (2012) found that work-related social maladjustment at SAS (Weissman \& Bothwell 1976) was associated with greater odds of death ideation for patients with higher levels of attachment avoidance, as measured with the Experiences in Close Relationships Scale (ECR) (Brennan et al. 1998). Parent-role related maladjustment was associated with greater odds of death ideation for those with lower levels of attachment anxiety. From this perspective, avoidant and anxious attachment orientations might be seen as moderator factors between social maladjustment and death ideation.

Fergusson et al. (2000), collecting data over the course of a 21-years longitudinal study, found a link between suicidal behaviors (in the age between 15 and 21 years) and five dimensions: 1) coming from socially disadvantaged backgrounds; 2 ) being exposed to problematical family circumstances during childhood (parental changes, childhood sexual abuse, parental alcohol problems and insecure attachment); 3) showing personality traits such as neuroticism and novelty-seeking; 4) showing mental health problems; 5) being exposed to recurrent adverse life events during adolescence. 
Salzinger et al. (2007) found that preadolescent physical abuse could be an independent risk factor for adolescent suicidal behaviors. Conversely, a history of positive relationships might be a protective factor. In this perspective, they focused on the protective role of parental attachment even in abused adolescents. Adolescent attachment to parents and internalizing problems contributed independently to the prediction of suicidality risk in abused and control subjects. No preadolescent risk or protective factors added to the predictions beyond risk deriving from preadolescent abuse.

More recently, Sheftall et al. (2013) examined the attachment patterns along with broader family functioning (family adaptability and cohesion) in a sample of 236 adolescent psychiatric inpatients with $(n=111)$ and without $(\mathrm{n}=125)$ history of suicide attempts. Compared to those without suicide attempts, adolescent attempters had lower levels of self-reported maternal and paternal attachment, and lower familial adaptability and cohesion. Paternal attachment was the only significant predictor of suicide attempt. Levi-Belz et al. (2013) found that both anxious and avoidant attachment patterns predicted medical lethality of suicidal behaviors.

The study of Palitsky et al. (2013) was the first to show, with a multiple logistic regression analysis on the National Comorbidity Survey Replication database (NCS-R, N=5692, aged $>18$ years), that subjects with an insecure adult attachment style might have an increased likelihood of suicidal behaviors (suicidal ideation or suicide attempt), mood, anxiety, eating disorders, impulse dyscontrol, and substance abuse (adjusted odds ratio range, 1.13-1.81). The AORs were larger for avoidant attachment (1.17-1.81) than for anxious attachment (1.131.74) (respectively, AOR, 1.13-1.81 and AOR, 1.131.67).

Following these observations, we hypothesize the different roles of three theoretical links that could mediate the relationship between attachment style and suicidality (Table 1).

\section{A neurobiological hypothesis: the role of oxytocin}

The neurobiological basis of a correlation between attachment and suicidality is still unclear. Heim et al. (2009) found that women who reported childhood emotional neglect showed significantly reduced levels of cerebrospinal oxytocin. Moreover, the correlation between salivary oxytocin levels in mothers and infants was moderated by the degree of mother-infant affect synchrony (Feldman et al. 2010). It has been hypothesized that oxytocin might play a role in the biology of attachment, not only in animal models but also in humans. A study with functional MRI examined the maternal brain responses to a standard infant cry. MRI revealed the activation of many of the same regions identified in rodent models of maternal behavior (Lorberbaum et al. 2002). Furthermore, a recent study suggested that mothers with an insecure/dismissing pattern of attachment might have impaired peripheral and central oxytocin production, that might account for reduced activation of reward processing regions in the brain, when presented with facial cues from their infant (Strathearn et al. 2009). Breastfeeding, that has been associated with an increase of endogenous oxytocin, might lead to an increased activation of the striatum in the presence of the tears of the child (Kim et al. 2011). Oxytocin seemed to have a role also in the pathogenesis of several psychiatric disorders that might raise the risk for suicidal behaviors, including depression (Ozsoy et al. 2009, Parker et al. 2010) and schizophrenia (Goldman et al. 2008).

Costa et al. (2009) found a positive association between the GG genotype of oxytocin receptor gene (OXTR) and unipolar depression. In this group, GG individuals showed high scores on Attachment Style Questionnaire factors (Feeney et al. 1994), that have been previously associated with depression. Moreover, the GG genotype was also associated with high levels of adult separation anxiety.

With regard to oxytocin plasma level, a study found a significant reduction of plasma oxytocin in depressed patients when compared to controls (Zetzsche et al. 1996). A second study found no significant difference between mean plasma levels of OXT in depressed patients and controls (Van Londen et al. 1997). Scantamburlo et al. (2007) reported a negative correlation between the levels of oxytocin plasma and ratings of depressive symptoms. Deisenhammer et al. (2012) assessed basal oxytocin plasma levels of patients with $(n=41)$ and without $(n=40)$ suicidal attempts during the last year. They found no significant differences between those with suicide attempts and those without, with regard to oxytocin plasma levels.

Although oxytocin is probably involved in the development of depression and in the determination of attachment styles, is not a promising candidate as peripheral biological marker for suicide attempts, and its definite role in the context of suicidality remains unclear.

\section{A clinical hypothesis: the role of adult separation anxiety}

Separation anxiety (SA), traditionally defined as a childhood condition, is conceptually rooted in both developmental research and attachment theory. Distress upon separation from one's attachment figure is the developmental norm during early childhood and considered as an evolutionarily adaptive mechanism designed to keep the defenseless child in close proximity to adult caregiver (Ainsworth 1973, Bowlby, 1973). Only when the separation distress becomes excessive, prolonged, and developmentally inappropriate or impairing, a psychiatric diagnosis is due. The estimated prevalence of childhood separation anxiety disorder (CSAD) is $4 \%$ (APA DSM-IV, 1994). Manicavasagar et al. (1996) proposed that the core symptoms of SA might persist or arise throughout adulthood. DSM-5 (2013) considered as possible a diagnosis of SAD in adults without a history of SAD in childhood or adolescence. 
Table 1. Studies of attachment patterns and suicidal thoughts/behaviors in adulthood and adolescence. Modified and updated from Sheftall et al. (2013)

\begin{tabular}{|c|c|c|c|c|}
\hline Authors & $\mathrm{n}$ & Sample & $\begin{array}{l}\text { Attachment } \\
\text { Measures }\end{array}$ & Results \\
\hline $\begin{array}{l}\text { de Jong } \\
\text { et al. } 1992\end{array}$ & 126 & $\begin{array}{l}\text { Undergraduates: healthy controls, } \\
\text { depressed without history of suicidal } \\
\text { thoughts or attempts, vs subjects with a } \\
\text { history of significant suicidal ideation } \\
\text { and/or attempts ( } \mathrm{n}=42 \text { for group) }\end{array}$ & IPPA & $\begin{array}{l}\text { Students with history of suicidal thoughts or suicidal } \\
\text { attempts had less secure attachment than controls } \\
(\mathrm{p}<0.05) \text {, but not than students with depression. } \\
\text { History of suicidality was more strongly associated } \\
\text { with family instability than with parental divorce. }\end{array}$ \\
\hline $\begin{array}{l}\text { Adam } \\
\text { et al. } 1996\end{array}$ & 133 & $\begin{array}{l}\text { Adolescent psychiatric patients, with } \\
\text { history of suicidal behavior }(n=16) \text {, } \\
\text { severe suicidal ideation }(n=64) \text {, or with } \\
\text { no a history of significant suicidal } \\
\text { ideation and/or attempts }(n=53)\end{array}$ & AAI & $\begin{array}{l}\text { The predominant attachment patterns of the suicidal } \\
\text { group were 'unresolved-disorganized' and } \\
\text { 'preoccupied'. The } 86 \% \text { of cases experienced } \\
\text { attachment-related trauma. Suicidal patients displayed } \\
\text { the highest levels of disorganization in reasoning } \\
\text { during the events description. }\end{array}$ \\
\hline
\end{tabular}

Lessard and Moretti 1998

West et al. 1999

Di Filippo \& Overholser 2000

Fergusson et al. 2000

Riggs \& Jacobvitz 2002

Salzinger et al. 2007

Stepp et al. 2008

Zeyrek et al. 2009

180 Students at Middle East Technical University (Turkey)

406 Psychiatric patients and non-psychiatric subjects with a history of suicide attempts $(n=48)$, self-injury $(n=43)$, both on psychiatric $(n=61)$, or with no suicide attempts/self interview injury $(n=254)$

Grunebaum et al. 2010

136 Patients with Major Depressive Episode AAS (MDE)

Lizardi et al. 2011
254 Adults with unipolar bipolar depression, AAS with $(n=119)$ or without $(n=135)$ history of suicide attempts ratings based

Subject with suicidal ideation were more likely to be structured classified with fearful or preoccupied attachment than Bartholomew subjects with no ideation. interviews (1990)

AAQ, PSS-Fr Perceived unavailability $(\mathrm{p}<0.001)$ and depressive symptomatology $(\mathrm{p}=0.001)$ predicted suicidal behaviors. High levels of angry distress were correlated with suicidal behaviors.

Maternal $(\mathrm{p}<0.02)$ and peer $(\mathrm{p}<0.001)$ attachments were predictors of suicidal ideation. After adjusting for depressive symptoms, attachment variables failed to contribute to additional variance in suicidal ideation

Adolescents who reported suicidal ideation or attempts showed the highest levels of insecure attachment $(\mathrm{p}<0.0001)$. Attachment at age 15 predicted suicidal ideation $(\mathrm{p}<0.0001)$ and suicide attempts $(\mathrm{p}<0.0001)$ at the age of 21 .

Parents 'preoccupied' or 'unresolved' were more likely to report suicidal ideation than those classified as 'secure'. 'Unresolved' and 'preoccupied' attachments were related to a history of abuse during childhood $(\mathrm{p}<0.004)$ or to a parental divorce $(\mathrm{p}<0.004)$.

Secure attachment to parents (not to peers) decreased the risk for suicidal ideation and attempts.

Anxious attachment was related to the occurrence of suicide attempts, self-injury or both. The presence of 'interpersonal problems' was a 'mediator' for this relationship.

Perceived probability of future suicidal behavior significantly correlated with 'preoccupied' $(\mathrm{p}<0.01)$ or 'fearful' $(\mathrm{p}<0.05)$ attachment.

Avoidant attachment predicted suicidal ideation at 3month follow-up $(\mathrm{p}=0.004)$ and suicide attempts during a 1-year follow-up $(\mathrm{p}=0.003)$

'Suicide attempters' had anxious attachment style more frequently than 'non-attempters' $(\mathrm{OR}=1.33$; $95 \% \mathrm{CI}=1.016-1.728 ; \mathrm{p}=0.038)$

IPPA: Inventory of Parent and Peer Attachment; AAI: Adult Attachment Interview; AAQ: Adolescent Attachment Questionnaire; PSS-fR: The Perceived Social Support Scale-Friends; AAS: Adults Attachment Scale; ECR: Experiences in Close Relationships scale; SAS: Social Adjustment Scale; RQ: The Relationship Questionnaire; ARS: Attachment Self Report 
Table 1. Continues

\begin{tabular}{|c|c|c|c|c|}
\hline Authors & $\mathrm{n}$ & Sample & $\begin{array}{l}\text { Attachment } \\
\text { Measures }\end{array}$ & Results \\
\hline $\begin{array}{l}\text { Smith } \\
\text { et al. } 2012\end{array}$ & 106 & $\begin{array}{l}\text { Women with Major Depression and } \\
\text { histories of sexual abuse during } \\
\text { childhood }\end{array}$ & ECR & $\begin{array}{l}\text { Work-related maladjustment at SAS was associated } \\
\text { with greater odd ratios of death ideation amongst } \\
\text { patients with lower levels of attachment avoidance. } \\
\text { Avoidant and anxious attachment were moderators } \\
\text { between social maladjustment and death ideation. }\end{array}$ \\
\hline $\begin{array}{l}\text { Levi-Belz } \\
\text { et al. } 2013\end{array}$ & 102 & $\begin{array}{l}\text { Patients }(n=35) \text { after a medically serious } \\
\text { suicide attempt (MSSA) vs a group of } \\
\text { patients }(\mathrm{N}=67) \text { after a medically non- } \\
\text { serious suicide attempt (MNSSA). }\end{array}$ & ECR & $\begin{array}{l}\text { Dimensions of insecure attachment were associated } \\
\text { with lethality of suicide attempt }(\mathrm{r}=0.30 ; \mathrm{p}<0.004 \text { for } \\
\text { anxious attachment; } \mathrm{r}=0.21 ; \mathrm{p}<0.039 \text { for avoidant } \\
\text { attachment). }\end{array}$ \\
\hline $\begin{array}{l}\text { Palitsky } \\
\text { et al. } 2013\end{array}$ & 5692 & $\begin{array}{l}\text { National Comorbidity Survey Replica- } \\
\text { tion Study (NCS) (aged >18 years) }\end{array}$ & ARS & $\begin{array}{l}\text { Insecure attachment was associated with the greater } \\
\text { reporting of suicidal ideation, suicidal attempts, and } \\
\text { psychiatric disorders. }\end{array}$ \\
\hline $\begin{array}{l}\text { Sheftall } \\
\text { et al. } 2013\end{array}$ & 236 & $\begin{array}{l}\text { Adolescent psychiatric inpatients with } \\
(\mathrm{n}=111) \text { and without }(\mathrm{n}=125) \text { history of } \\
\text { suicide attempts. }\end{array}$ & IPPA & $\begin{array}{l}\text { Attempters had lower self-reported maternal }(\mathrm{p}=0.03) \\
\text { and paternal }(\mathrm{p}=0.01) \text { attachment and lower familial } \\
\text { adaptability }(\mathrm{p}=0.04) \text { and cohesion }(\mathrm{p}=0.001) \text { than } \\
\text { non-attempters }\end{array}$ \\
\hline
\end{tabular}

IPPA: Inventory of Parent and Peer Attachment; AAI: Adult Attachment Interview; AAQ: Adolescent Attachment Questionnaire; PSS-fR: The Perceived Social Support Scale-Friends; AAS: Adults Attachment Scale; ECR: Experiences in Close Relationships scale; SAS: Social Adjustment Scale; RQ: The Relationship Questionnaire; ARS: Attachment Self Report

Adult $\mathrm{SAD}$, for long relatively rarely diagnosed in clinical practice, had a lifetime prevalence in U.S population of $6.6 \%$ (Shear et al. 2006), while in one Italian clinical sample was $42.4 \%$ (Pini et al. 2010) and adult SAD comprised $23 \%$ of all diagnoses made in a suburban Sydney anxiety clinic (Silove et al. 2010).

Early separation anxiety of a severe type might increase the risk for distortions in developing personalities, especially in the area of interpersonal insecurity. The finding of a recent study supported this hypothesis: individuals with ASAD reported enduring styles of anxious attachment bonding, established in early development (Schulze et al. 2002).

The psychological literature on attachment (Dozier et al. 1999) and several previous retrospective studies showed that SA might be associated with a broad range of adult psychiatric conditions (Gittelman \& Klein 1984, Shear 1996, Bandelow et al. 2001, Pini et al. 2010, Miniati et al. 2012).

Separation anxiety, as clinical entity, might be the key for the comprehension of the relationship between insecure attachment and suicidality. The only study that addressed this point, to the best of our knowledge, was an Indian prospective study that collected data from 500 adolescents in a therapy community (Russel et al. 2013). The authors found that (as well as other anxiety disorders) separation anxiety increased the risk for suicidal behaviors.

\section{The continuum hypothesis: psychopathological dimensions and attachment style}

One interesting hypothesis that, in our opinion, has not been sufficiently explored in the literature was that the presence of certain psychopathological dimensions could mediate the relationship between attachment style and suicidality. The majority of studies did not consider that the presence of suicidal ideation could be related to a close relationship between dysfunctional attachment and an underling spectrum of psychopathological dimensions.

Warren et al. (1997) considered the association between attachment in infancy and the development of early onset anxiety disorders. They found that infants with resistant attachment were more likely to be diagnosed with anxiety disorders, than infants with secure or avoidant attachment, even when differences in temperament were controlled. Carlson (1998) suggested that children frequently hyper-aroused when threatened with an unavailable caregiver might develop a sensitized neurobiology predisposing to a subsequent anxiety disorder.

Brown \& Harris (1993) found that patients with Panic Disorder frequently experienced the loss of a caregiver or an extremely inadequate care giving. Cassidy (1995) reported that patients with Generalized Anxiety Disorder (GAD) described a subjective feeling of rejection by their parents. More in general, patients with anxiety disorders represented their parents as unloving and controlling (Chambless et al. 1996). Unfortunately, no specific anxiety disorders were linked to a specific parental care model.

Several studies investigated the association between states of mind and anxiety disorders. Rosenstein \& Horowitz (1996) found, in a sample of anxious patients, that $65 \%$ had preoccupied states of mind and $35 \%$ had dismissing states of mind. The discourse of adults who were preoccupied with regard to attachment was affected by anxiety diffuse, as in GAD or focused as in Panic Disorder (Cassidy 1995). Separation sensitivity traits, excessive dependence on attachment figures and anxiety linked to separation correlated with the development of complicated grief (Vanderwerker et al. 2006). 
The association between attachment and dissociation seemed to have an adaptive function, allowing not to become overwhelmed by a trauma. After repeated episodes of threats, children might experience at first alarm and hyper arousal of sympathetic nervous system, then helpless. Finally, behavioral reaction could be characterized by freezing and a trance-like state (Perry et al. 1995). Several studies hypothesized that experiencing dissociative states during childhood could sensitize and compromise the neural networks, predisposing individuals to experiencing later dissociative states. Carlson (1998) found a strong association between disorganized attachment in infancy and dissociative symptoms in the Minnesota longitudinal sample, while no association was found between disorganized attachment and endogenous vulnerability (prenatal difficulties, difficulties occurred during childbirth or maternal drug/alcohol use). According to Main \& Hesse (1990), disorganized behavior during a strange situation could be the result from caregiver's behaving toward the child (in a frightened or frightening way): an unresolved caregiver with regard to attachment was unable to protect adequately the child. In addition, disorganized children might be at higher risk for later abuse, and children with disorganized attachment might develop dissociative disorders when abused.

Patients with borderline personality disorder might have preoccupied states of mind, especially when a traumatic event occurred. They frequently report physical or sexual abuse (Herman et al. 1989), prolonged separation from caregivers (Zanarini et al. 1989), or emotional neglect (Patrick et al. 1994).

Patients with antisocial personality disorder might have experienced during childhood-prolonged separation with frightening threats (Bowlby 1973), physical abuse or harsh discipline (Zanarini et al. 1989). Subsequently, they might develop a particular dismissing attachment called 'derogation of attachment'.

Reports of abuse are frequent amongst borderline personality disorder, dissociative disorder and antisocial personality disorder patients. Extended abuse occurs in a context of disordered care giving (Alexander 1992). Dissociation seems to mediate the relationship between children sexual abuse (CSA), drug/alcohol abuse, and suicidality (Rodriguez-Srednicki 2001).

Patients with Eating Disorders (ED) are frequently described as dismissing (Fonagy et al. 1996) with a family characterized by a mother domineering and overprotective and a father emotionally unavailable and rejecting. Stein and Colleagues (2013) investigated the correlation between ED and suicidality, underlining that suicidal attempters with ED showed more binge/purge behaviors. Suicide attempters with anorexia nervosa (AN) were older, with longer illness duration, and tended to be more obsessive than non-attempters. Attempters with bulimia nervosa $(\mathrm{BN})$ frequently reported on sexual abuses (Favaro \& Santonastaso 1997).

The association between attachment styles and schizophrenia is still unclear. Double binding-communication, communication deviance and expressed emotions are considered the result of parents' difficulty of approaching to children with sub-threshold features (Bateson et al. 1956, Goldstein 1985, Walker et al. 1993). Patients with schizophrenia show dismissing/unresolved attachment (Dozier et al. 1994) compromised by the patients' thought disorders (incoherence, illogicality).

In summary, psychiatric disorders are frequently associated with non-autonomous states of mind and the unresolved status is over-represented. However, the connection between infant attachment and adult psychopathology might become manifest when a correlation between disorganized attachment and dissociative symptoms or resistant attachment and anxiety is present. In our opinion, future research should assess psychopathology and attachment pattern at the same time, not overlooking the presence of suicidal ideation and attempts, beyond the patterns of present attachment (Mikulincer \& Shaver 2012).

\section{CONCLUSIONS}

Systematic studies are needed to highlight the nature of the link between attachment and suicide related behaviors. Future researches should consider the relationship between signs and symptoms of the most relevant psychopathological areas in adulthood, and the presence of altered attachment patterns in a lifetime perspective. We believe that the presence of suicidal ideation and attempts is the consequence of an underlying interaction between the occurrence of signs and symptoms belonging to different psychopathological areas, and the long-lasting presence of inadequate patterns of attachment. Separation anxiety disorder may represent a bridge between insecure attachment and suicide.

\section{Acknowledgements:}

This work received no grant from any funding agency, commercial or not-for-profit sectors.

\section{Conflict of interest: None to declare.}

\section{Contribution of individual authors:}

Mario Miniati, Antonio Callari and Stefano Pini made substantial contributions to the analysis and interpretation of data, and have been involved in drafting the manuscript or revising it critically for important intellectual content. All authors read and approved the final manuscript.

\section{References}

1. Achenbach TM: Manual for the Youth Self-Report and 1991 profile. Burlington, University of Vermont, 1991.

2. Adam KS. Childhood parental loss, suicidal ideation and suicidal behavior. In Anthony EJ \& Koupernik C (eds): The child in his family; the impact of disease and death, 275-97. Wiley, New York, 1973. 
3. Adam KS: Suicide behavior and attachment: A developmental mode. In Sperling MD \& Berman $H$ (eds): Attachment and adults: theory, assessment and treatment, 275-98. Guilford, New York, 1994.

4. Adam KS, Sheldon-Keller AE, West M: Attachment organization and history of suicidal behavior in clinical adolescents. J Consult Clin Psychol 1996; 64:264-72.

5. Ainsworth MDS: The development of infant-mother attachment. In Caldwell $B$ \& Ricciuti $H$ (eds): Review of Child Development Research, 1-94. University of Chicago Press, Chicago, 1973.

6. Alexander PC: Application of attachment theory to the study of sexual abuse. J Consult Clin Psychol 1992; 60:185-95.

7. American Psychiatric Association. Diagnostic and Statistical Manual of Mental Disorders, 4th edition. American Psychiatric Press, Washington DC, 1994.

8. American Psychiatric Association. Diagnostic and Statistical Manual of Mental Disorders, Fifth Edition. American Psychiatric Press, Washington DC, 2013

9. Armsden GC, Greenberg, MT: The Inventory of Parent and Peer Attachment: Individual differences and their relationship to psychological well-being in adolescence. $J$ Youth Adolesc 1987; 16:427-54.

10. Bandelow B, Alvarez Tichauer G, Späth C, Broocks A, Hajak $G$, Bleich $S$, et al.: Separation anxiety and actual separation experiences during childhood in patients with panic disorder. Can J Psychiatry 2001; 46:948-52.

11. Bateson G, Jackson D, Haley J, Weakland J: Toward a theory of schizophrenia. Behav Science 1956: 1:251-64.

12. Beck AT, Ward CH, Mendelson M, Mock J, Erbaugh J: An inventory for measuring depression. Arch Gen Psychiatry 1961; 4:561-71.

13. Beck AT, Steer RA: Manual for Beck Scale for Suicide Ideation. Psychological Corporation, New York, 1991.

14. Blatt SJ, Levy KN: Attachment theory, psychoanalysis, personality development, and psychopathology. Psychoanal Inquiry 2003; 23:102-50.

15. Bongar B, Goldberg L, Cleary K, Brown L: Marriage, family, family therapy, and suicide. In Maris $R W$, Berman AL, Silverman MM (eds): Comprehensive Textbook of Suicidology, 222-39. The Guilford Press, New York, 2000.

16. Bowlby J: Attachment and loss. Vol. I. Attachment. Basic Books, New York, 1969.

17. Bowlby J. Attachment and Loss: Vol. 2. Separation. Basic Books, New York, 1973.

18. Brennan KA, Clark CL, Shaver PR: Self-report measurement of adult attachment: An integrative overview. Guilford Press, New York, 1998.

19. Brown GW, Harris TO: Etiology of anxiety and depressive disorders in an inner-city population. Early adversity. Psychol Med 1993; 23:143-54.

20. Carlson EA: A prospective longitudinal study of attachment disorganization/disorientation. Child Dev 1998; 69:1107-28.

21. Cassidy J: Attachment and generalized anxiety disorder. In Cicchetti D \& Toth $S$ (eds): Rochester Symposium on developmental psychopathology: vol.6. Emotion, cognition and representation, 343-70. Rochester, University of Rochester Press, NY, 1995.

22. Chambless DL, Gillis MM, Tran GQ, Steketee GS: Parental bonding reports of clients with obsessive compulsive disorder and agoraphobia. Clin Psychol Psychother 1996; 3:77-85.
23. Costa B, Pini S, Gabelloni P, Abelli M, Lari L, Cardini A, et al.: Oxytocin receptor polymorphisms and adult attachment style in patients with depression. Psychoneuroendocrinology 2009; 34:1506-14.

24. de Haas MA, Bakermans-Kranenburg MJ, van Ijzendoorn MH, Main M: The Adult Attachment Interview and questionnaires for attachment style, temperament, and memories of parental behavior. J Genet Psychol 1994; 155: 471-86.

25. de Jong ML: Attachment, individuation, and risk of suicide in late adolescence. J of Youth Adolesc 1992; 21:357-73.

26. Deisenhammer EA, Hofer S, Schwitzer O, Defrancesco M, Kemmler G, Wildt L, et al.: Oxytocin plasma levels in psychiatric patients with and without recent suicide attempt. Psychiatry Res 2012; 200:59-62.

27. DiFilippo JM, Overholser JC: Suicidal ideation in adolescent psychiatric inpatients as associated with depression and attachment relationships. J Clinical Child Psychol 2000; 29:155-66.

28. Dozier M, Cue KL, Barnett L: Clinicians as caregivers: role of attachment organization in treatment. $J$ Consult Clin Psychology 1994; 62:793-800.

29. Dozier M, Chase Stovall K, Albus K. Attachment and psychopathology in adulthood. In Cassidy $J \&$ Shaker PR (eds): Handbook of Attachment, 497-519. Guilford Press, New York, 1999.

30. Favaro A, Santonastaso P: Suicidality in eating disorders: clinical and psychological correlates. Acta Psychiatr Scand 1997; 95: 508-14.

31. Feeney JA, Noller P, Hanrahan M: Assessing adult attachment. In Sperling $M B$ an\&d Berman WH (eds): Attachment in Adults: Clinical and Developmental Perspectives, 128-52. Guilford Press, New York, 1994.

32. Feldman R, Gordon I, Zagoory-Sharon O: The crossgeneration transmission of oxytocin in humans. Horm Behav 2010; 58:669-76.

33. Fergusson DM, Woodward LJ, Horwood LJ. Risk factors and life processes associated with the onset of suicidal behaviors during adolescence and early adulthood. Psychol Med 2000; 30:23-39.

34. Fonagy $P$, Leigh $T$, Steele $M$, Steele $H$, Kennedy $R$, Mattoon $G, T$, et al.: The relation of attachment status, psychiatric classification, and response to psychotherapy. J Consult Clin Psychol 1996; 64:22-31.

35. Gittelman R, Klein D: Relationship between separation anxiety and panic and agoraphobic disorders. Psychopathology 1984; 17:56-65.

36. Goldman M, Marlow-O'Connor M, Torres I, Carter CS: Diminished plasma oxytocin in schizophrenic patients with neuroendocrine dysfunction and emotional deficits. Schizophrenia Res 2008; 98:247-55.

37. Goldstein MJ: Family factors that antedate the onset of schizophrenia and related disorders: the results of a fifteen-year prospective longitudinal study. Acta Psychiatr Scand Suppl 1985; 319:7-18.

38. Grunebaum MF, Galfalvy HC, Mortenson LY, Burke AK, Oquendo MA, Mann JJ: Attachment and social adjustment: relationships to suicide attempt and major depressive episode in a prospective study. J Affect Disord 2010; 12:123-30.

39. Heim C, Young LJ, Newport DJ, Mletzko T, Miller AH, Nemeroff CB: Lower CSF oxytocin. Concentrations in women with a history of childhood abuse. Mol Psychiatry 2009; 14:954-58. 
40. Herman JL, Perry JC, van der Kolk BA: Childhood trauma in borderline personality disorder. Am $J$ Psychiatry 1989; 146:490-95.

41. Kim P, Feldman R, Mayes LC, Eicher V, Thompson N, Leckman JF, et al.: Breastfeeding, brain activation to own infant cry, and maternal sensitivity. $J$ Child Psychol Psychiatry 2011; 52:907-15.

42. Kovacs M: Children's Depression Inventory. Multi-Health Systems. North Tonawanda, 1992.

43. Lessard JC, Moretti MM: Suicidal ideation in an adolescent clinical sample: attachment patterns and clinical implications. J Adolesc 1998; 21:383-95.

44. Levi-Belz Y, Gvion Y, Horesh N, Apter A: Attachment Patterns in Medically Serious Suicide Attempts: The Mediating Role of Self-Disclosure and Loneliness. Suic Life Threat Behav 2013; 43:511-22.

45. Lizardi D, Grunebaum MF, Burke A, Stanley B, Mann JJ, Harkavy-Friedman J, et al: The effect of social adjustment and attachment style on suicidal behaviour. Acta Psychiatr Scand 2011; 124:295-300.

46. Lorberbaum JP, Newman JD, Horwitz AR, Dubno JR, Lydiard RB, Hamner $M B$, et al.: A potential role for thalamocingulate circuitry in human maternal behavior. Biol Psychiatry 2002; 51:431-45.

47. Main M, Hesse E: Parents' unresolved traumatic experiences are related to infant disorganized attachment status: Is frightened and/or frightening parental behavior the linking mechanism? In Greenberg M, Cicchetti D \& Cummings EM (eds): Attachment in the preschool years, 161-82. University of Chicago Press, Chicago, 1990.

48. Manicavasagar V, Silove D, Curtis J: Separation anxiety in adulthood: a phenomenological investigation. Compr Psychiatry 1996; 38:274-82.

49. Mann JJ, Waternaux C, Haas GL, Malone KM: Toward a clinical model of suicidal behavior in psychiatric patients. Am J Psychiatry 1999; 156:181-89.

50. Mikulincer M, Shaver PR: Attachment in Adulthood. The Guilford Press, New York, 2007.

51. Mikulincer M, Shaver PR. An attachment perspective on psychopathology. World Psychiatry 2012; 11:11-5.

52. Miniati M, Calugi S, Rucci P, Shear MK, Benvenuti A, Santoro D, et al.: Predictors of response among patients with panic disorder treated with medications in a naturalistic follow-up: the role of adult separation anxiety. J Affect Disord 2012; 136:675-79.

53. Office of the Surgeon General (US), National Action Alliance for Suicide Prevention (US). National Strategy for Suicide Prevention: Goals and Objectives for Action: A Report of the U.S. Surgeon General and of the National Action Alliance for Suicide Prevention, US Department of Health and Human Services (US), Washington (DC), 2012.

54. Offord DR, Boyle MH, Szatmari P, Rae-Grant NI, Links PS, Cadman DT, et al: Ontario Child Health Study. II. Six-month prevalence of disorder and rates of service utilization. Arch Gen Psychiatry 1987; 44:832-36.

55. Ozsoy S, Esel E, Kula M: Serum oxytocin levels in patients with depression and the effects of gender and antidepressant treatment. Psychiatry Res 2009; 169:24952.

56. Palitsky D, Mota N, Afifi TO, Downs AC, Sareen J: The association between adult attachment style, mental disorders, and suicidality: findings from a populationbased study. J Nerv Ment Dis 2013; 201:579-86.
57. Parker KJ, Kenna HA, Zeitzer JM, Keller J, Blasey CM, Amico JA, et al.: Preliminary evidence that plasma oxytocin levels are elevated in major depression. Psychiatry Res 2010; 178:359-62.

58. Patrick M, Hobson RP, Castle D, Howard R, Maughan B: Personality disorder and the mental representation of early social experience. Dev Psychopathol 1994; 6:375-88.

59. Perry BD, Pollard R, Blackley TL, Baker WL, Vigilante D: Childhood trauma, the neurobiology of adaptation, and "use dependent" development of the brain: How "states" become "traits". Inf Ment Health Journal 1995; 16:271-91.

60. Pini S, Abelli M, Shear KM, Cardini A, Lari L, Gesi C, et al: Frequency and clinical correlates of adult separation anxiety in a sample of 508 outpatients with mood and anxiety disorders. Acta Psychiatr Scand 2010; 122:40-6.

61. Riggs SA, Jacobvitz D: Expectant parents' representations of early attachment relationships: associations with mental health and family history. J Consult Clin Psychol 2002; 70:195-204.

62. Rodriguez-Srednicki O: Childhood sexual abuse, dissociation, and adult self-destructive behavior. J Child Sex Abuse 2001; 10:75-90.

63. Rosenstein DS, Horowitz HA: Adolescent attachment and psychopathology. J Consult Clin Psychol 1996; 64:244-53.

64. Russell PS, Nair MK, Chandra A, Subramaniam VS, Bincymol K, George B, et al.: ADad 9: Suicidal Behavior in Anxiety Disorders Among Adolescents in a Rural Community Population in India. Indian J Pediatr 2013; 2:175-80.

65. Salzinger $S$, Rosario M, Feldman RS, Ng-Mak DS: Adolescent suicidal behavior: associations with preadolescent physical abuse and selected risk and protective factors. J Am Acad Child Adolesc Psychiatry 2007; 46:859-66.

66. Scantamburlo G, Hansenne M, Fuchs S, Pitchot $W$, Marechal P, Pequeux C, et al.: Plasma oxytocin levels and anxiety in patients with major depression. Psychoneuroendocrinology 2007; 32:407-10.

67. Schulze TG, Müller DJ, Krauss H, Gross M, FangerauLefèvre H, Illes F, et al.: Further evidence for age of onset being an indicator for severity in bipolar disorder. J Affect Disord 2002; 68:343-45.

68. Shear MK: Factors in the aetiology and pathogenesis of panic disorder: Revisiting the attachment-separation paradigm. Am J Psychiatry 1996; 153:125-35.

69. Shear MK, Jin R, Ruscio AM, Walters EE, Kessler RC: Prevalence and correlates of estimated DSM-IV child and adult separation anxiety disorder in the National Comorbidity Survey Replication. Am J Psychiatry 2006; 163:1074-83.

70. Sheftall AH, Mathias CW, Furr RM, Dougherty DM: Adolescent attachment security, family functioning, and suicide attempts. Attach Human Dev 2013; 15:368-83.

71. Silove DM, Marnane CL, Wagner R, Manicavasagar VL, Rees $S$ : The prevalence and correlates of adult separation anxiety disorder in an anxiety clinic. BMC Psychiatry 2010; 10:21.

72. Simpson JA: Influence of attachment styles on romantic relationships. J Pers Soc Psychol 1990; 59:971-80.

73. Smith PN, Gamble SA, Cort NA, Ward EA, Conwell Y, Talbot NL: The relationships of attachment style and social maladjustment to death ideation in depressed women with a history of childhood sexual abuse. J Clin Psychol 2012; 68:78-87. 
74. Sroufe LA: Attachment and development: A prospective, longitudinal study from birth to adulthood. Attach Hum Dev 2005; 7:349-67.

75. Stein D, Zinman D, Halevy L, Yaroslavsky A, Bachar E, Kreitler $S$, et al.: Attitudes toward life and death and suicidality among inpatient female adolescents with eating disorders. J Nerv Ment Dis 2013; 201:1066-71.

76. Stepp SD, Morse JQ, Yaggi KE, Reynolds SK, Reed LI, Pilkonis PA: The role of attachment styles and interpersonal problems in suicide-related behaviors. Suicide Life Threat Behav 2008; 38:592-607.

77. Strathearn L, Abdullah M, Najman JM, O'Callaghan M: Does breastfeeding protect against substantiated child abuse and neglect? A 15-year cohort study. Pediatrics 2009; 123:483-93.

78. Van Londen L, Goekoop JG, van Kempen GM, Frankhuijzen-Sierevogel AC, Wiegant VM, van der Velde EA, et al.: Plasma levels of arginine vasopressin elevated in patients with major depression. Neuropsychopharmacology 1997; 17:284-92.

79. Vanderwerker LC, Jacobs SC, Parkes CM, Prigerson HG: An exploration of associations between separation anxiety in childhood and complicated grief in later life. J Nerv Ment Dis 2006; 194:121-23.

80. Walker EF, Grimes KE, Davis DM, Smith AJ: Childhood precursors of schizophrenia: facial expressions of emotion. Am J Psychiatry 1993; 150:1654-60.
81. Ward MJ, Lee SS, Polan HJ: Attachment and psychopathology in a community sample. Attach Hum Dev 2006; 8:327-40.

82. Warren SL, Huston L, Egeland B, Sroufe LA: Child and adolescent anxiety disorders and early attachment. J Am Acad Child Adolesc Psychiatry 1997; 36:637-44.

83. Weissman MM: The epidemiology of suicide attempts, 1960 to 1971. Arch Gen Psychiatry 1974; 30:737-46.

84. Weissman MM, Bothwell S: Assessment of social adjustment by patient self-report. Arch Gen Psychiatry 1976; 33:1111-15.

85. West M, Rose MS, Spreng S, Sheldon-Keller A, Adam K: Adolescent attachment questionnaire: A brief assessment of attachment in adolescence. J Youth Adolesc 1998; 27:661-73.

86. West ML, Spreng SW, Rose SM, Adam KS: Relationship between attachment-felt security and history of suicidal behaviors in clinical adolescents. Can J Psychiatry 1999; 44: $578-82$.

87. Zanarini MC, Gunderson JG, Marino MF, Schwartz EO, Frankenburg FR: Childhood experiences of borderline patients. Compr Psychiatry 1989; 30:18-25.

88. Zetzsche T, Frasch A, Jirikowski G, Murck H, Steigner A: Nocturnal oxytocin secretion is reduced in major depression. Biol Psychiatry 1996; 39:584.

89. Zeyrek EY, Gençöz F, Bergman Y, Lester D: Suicidality, problem-solving skills, attachment style, and hopelessness in Turkish students. Death Studies 2009; 9:815-27.

\section{Correspondence:}

Mario Miniati, MD, Adjunct Professor

Department of Clinical and Experimental Medicine,

Section of Psychiatry, University of Pisa

Via Roma, 67, 56126 Pisa, Italy

E-mail:mario.miniati@med.unipi.it 